\title{
A Control Model for Reinforced Concrete Work Materials on the Construction of Duta Mall 2
}

\author{
Sudiono Daslim \\ Department of Civil Engineering \\ Faculty of Engineering \\ Lambung Mangkurat University \\ Banjarmasin, Indonesia \\ sudiono_daslim@yahoo.com
}

\author{
Aqli Mursadin \\ Department of Civil Engineering \\ Faculty of Engineering \\ Lambung Mangkurat University \\ Banjarmasin, Indonesia \\ a.mursadin@ulm.ac.id
}

\begin{abstract}
Controlling is a crucial stage in achieving a project target, covering aspects of cost, quality, and time. In the construction industry, the cost aspect is often the main focus. The project of Duta Mall 2 (DM 2) is the development of an existing building and the cost aspect is a major concern to the owner. Dynamic internal and external factors of the DM 2 project cause the project control to be quite difficult, with the materials becoming the most dominant factor in construction cost. Cost control starts from reinforced concrete work materials, consisting of ready mixed concrete, concrete steel, wire, plywood, timber, and nails. Bad control of material purchasing can lead to cost escalation, degradation of material quality, and impact on the execution schedule of works. This research was conducted to obtain quantitative correlations between material components based on reinforced concrete works material supply data. From these data, some linear regression models can be designed to obtain a more accurate and effective prediction of material volume needs in the future. Model equations can be applied to control material demand, measure waste, reference of material volume in arranging the project cost budget, in addition to the process in the control procedure of the request for goods (materials and equipment).
\end{abstract}

Keywords-reinforced concrete works; material control; linear regression; predictive capabilities; control procedure

\section{INTRODUCTION}

On all construction projects, cost, quality and time are parameters that need to be optimized. Cost is a very important project parameter. It stands as a single aspect and is also influenced by the quality and completion time of works. Poor quality works will lead to complaints and can potentially create a construction claim or at least a demand of reworks/repairs which will lead to cost overrun. Delay in project completion will cause cost overrun or even a fine. Cost management is a completion of three constraints covering cost, schedules, and scope. Each must be completed in order to complete the project on time and budget and meet all customer expectations. Projects must be settled on an approved budget. It is therefore very clear that the quality problem and the work schedule will also affect the cost [1]. Duta Mall 2 (DM 2) is a building construction project. It is the expansion of Duta Mall 1 (DM 1) which is already in operation. In this dynamic DM 2 project, there are several factors that cause difficulty in material control. Material management, especially for reinforced concrete works in the DM 2 project, is done by the contractor but its purchase system is controlled by a management team from the owner to minimize cost. Besides the cost aspect, the material management system also touches integrated environmental and social aspects [2]. Material control of reinforced concrete works is very important, because the material cost is a significant part of the overall cost of the project, representing anything from $40 \%$ to $60 \%$ of the final cost, so tight control is essential [3]. Based on the historical data on material supply of reinforced concrete works in DM 2, there are some regression models of volume supply of the materials. Material components of reinforced concrete works consist of ready mixed concrete, concrete steel, wire, plywood, timber and nails. The aims of the current research are:

- To find the various causes of difficulty in material control of reinforced concrete works on the development of DM 2 based on the existing procedure.

- To develop a relationship model of volume supply between materials on the construction of DM 2.

- To improve material planning procedures and control on reinforced concrete works in DM 2 project.

\section{THEORITICAL BASIS}

\section{A. Project Management and Project Control}

A project is defined as a temporary effort made to create unique products, services or results [4]. It is defined by PMBOK (Project Management Body of Knowledge). Project management aims to plan, to organize, to lead, and to control company resources to achieve a predetermined short-term goal [5]. Control of construction project includes cost, quality, and time. The concept of controlling the project in the lean construction method has a principle in downsizing or reducing/eliminating waste. Construction waste is anything generated as a result of construction and is then abandoned, regardless weather it has been processed or stockpiled [6].

\section{B. Material Control on Construction Projects}

In the production system, especially in the construction 
industries related to supply chain management, there are two methods, i.e. push system and pull system. The DM 2 construction project utilizes a combination of both methods. Controlling of reinforced concrete work materials to optimize construction project cost can be achieved by the following process:

- Fulfillment of demand or submission of materials.

- Estimation of inventory according to the job stage or work schedule that has been planned some time ahead.

- Supervision of material acceptance to fit the demand.

- Storage and protection of materials.

- Efficiency of material use in the project through appropriate supervision and working methods.

- Evaluation of progressive material usage.

The ability to control reinforced concrete work materials certainly increases the effectiveness of the contractor. In addition to economic reasons, effective material control also reduces material waste. Material cost, delay of material arrival and inaccurate estimates are examples of causes of cost overrun [7]. The objective is to assure that the right materials in the right quantities and at the right locations are provided at the right time to the construction crews on the project. Most construction site layout planning for construction sites is based upon contractors' prior experience and it is designed only once before construction starts without consideration of the dynamic nature of the supply problems, such as dynamic changes of requirements and available site information in consecutive construction project phases [8]. Material procurements on several projects also have constraints on the availability of location in the field. Adequate supply of materials in accordance with the planned job site will help the implementation of construction effectively and efficiently. However, in some projects the stages of construction activities may differ from the initial planning, due to the dynamic implementation of construction. Consequently, there is a distortion between the material supplies previously proposed based on estimates and the new areas of the work.

\section{Simple Linear Regression Model}

In the construction industry, some problems have relationships that can be predicted through regression models. The relationship between a variable in a group and other groups is often very useful in statistical analysis. The relationship between the independent variable and the matched response is an equation of regression [9]. Steps or stages that need to be conducted in order to obtain a good linear regression model consist of model identification, parameter estimation, parameter testing, and application of regression models [10].

\section{RESEARCH METHOD}

In this research, preliminary analysis is applied to the recapitulation acceptance data of reinforced concrete materials, i.e. ready mixed concrete, concrete steel, wire, plywood, timber, and nails with the scatter plot method. Parameter estimation for linear regression models was conducted with the least squares method and validation followed [11]. The formed linear regression model was adopted into the pre-existing model of the DM 2 materials control procedure. The implementation steps of the research are:

- Preliminary study, in the form of observations in the field (Project DM 2).

- Literature review.

- Primary and secondary data collection.

- Study of the causes of difficulty in controlling reinforced concrete work materials by observation of the work processes and materials used.

- Regression model construction based on the supply data.

- Validation of the linear regression models.

- Model of planning and material volume control.

- Conclusion.

\section{DATA ANALYSIS}

\section{A. Initial Data Collection}

The materials of reinforced concrete works are exhibited in Table I along with the periodic data which must be transformed in cumulative data. The cumulative data of each material have been tested for normality distribution as shown in Table II.

\section{B. Developing of Linear Regression Models}

\section{1) Regression Equations of Reduction Data Constructed with the Least Squares Method}

In developing linear regression models, the research uses the cumulative data, so the periodic data should be modified or transformed. Table II shows that models for plywood-timber and timber-nails do not pass the normality test. The $\mathrm{P}$ values for both data pairs are less than 0.05 , which means that the data have non-normal distribution. Therefore it is necessary to reduce outlier data. The data that should be eliminated for the above models are described below.

- Plywood-timber: Data that should be eliminated are variable no. 12 (December 2017) and no. 15 (March 2018).

- Timber-nails: Data that should be eliminated are only variable no. 12 (data on December 2017).

After eliminating the outlier data, the normality tests for both models are fulfilled. Next, the used data are normally distributed variables that generate the following equations:

- Ready mixed concrete and concrete steel:

$$
\hat{Y}_{S}=-109.92+0.1787 X c
$$

- Concrete steel-wire:

$$
\hat{Y} w=1,885.25+7.6577 X s
$$

- Ready mixed concrete-plywood:

$$
\hat{Y} p=-358.95+0.4228 X c
$$


TABLE I. SUPPLY OF REINFORCED CONCRETE WORK MATERIALS

\begin{tabular}{|c|c|c|c|c|c|c|c|}
\hline No. & Month & Ready mixed concrete $\left(\mathrm{m}^{3}\right)$ & Concrete steel $(\times 1000 \mathrm{~kg})$ & Wire (kg) & Plywood (pes) & Timber $\left(\mathrm{m}^{3}\right)$ & Nails (kg) \\
\hline 1 & Jan'17 & $1,653.5$ & 182.513 & 2,780 & 546 & 56.11 & 1,125 \\
\hline 2 & Feb'17 & 715.0 & 244.771 & 200 & 294 & 64.03 & 1,040 \\
\hline 3 & Mar'17 & 890.5 & 44.746 & 1,500 & 104 & 20.01 & 695 \\
\hline 4 & Apr'17 & 815.0 & 167.096 & 1,400 & 448 & 4.31 & 770 \\
\hline 5 & May'17 & 896.0 & 63.952 & 1,300 & 240 & 11.00 & 695 \\
\hline 6 & Jun'17 & 355.5 & 190.131 & 800 & - & 6.11 & 270 \\
\hline 7 & Jul' 17 & 211.0 & - & 110 & 60 & 33.00 & - \\
\hline 8 & Aug'17 & $1,067.0$ & 145.029 & 1,830 & 583 & 84.50 & 860 \\
\hline 9 & Sep'17 & 948.5 & 297.365 & 1,050 & 528 & 65.70 & 1,040 \\
\hline 10 & Oct'17 & 509.5 & 455.435 & 1,800 & 150 & 42.30 & 520 \\
\hline 11 & Nov'17 & $1,125.0$ & - & 1,550 & 607 & 72.45 & 1,130 \\
\hline 12 & Dec'17 & 952.5 & 112.619 & 600 & 304 & 184.18 & 510 \\
\hline 13 & Jan'18 & $1,764.5$ & - & 3,150 & 832 & 136.91 & 1,650 \\
\hline 14 & Feb'18 & $1,587.5$ & 218.068 & 1,100 & 900 & 85.81 & 1,550 \\
\hline 15 & Mar'18 & $1,402.5$ & 415.649 & 2,100 & 252 & 151.30 & 2,330 \\
\hline 16 & Apr'18 & $1,579.5$ & - & 2,150 & 1,202 & 101.06 & 1,205 \\
\hline 17 & May'18 & 827.5 & 177.642 & 1,500 & 165 & 33.11 & 827 \\
\hline 18 & Jun'18 & 346.0 & 144.040 & - & - & - & - \\
\hline 19 & Jul'18 & 599.5 & 135.359 & 2,100 & 150 & 38.14 & 1,706 \\
\hline 20 & Aug'18 & $1,543.5$ & - & 2,700 & 391 & 63.75 & 1,363 \\
\hline 21 & Sep'18 & 969.5 & 567.687 & 600 & 510 & 12.54 & 1,200 \\
\hline 22 & Oct'18 & $1,297.5$ & 60.561 & 1,600 & 820 & 38.31 & 170 \\
\hline 23 & Nov'18 & 973.0 & 313.245 & 1,200 & 300 & 19.28 & 814 \\
\hline 24 & Dec'18 & $1,135.5$ & 260.196 & 1,700 & 150 & 31.04 & 520 \\
\hline 25 & Jan'19 & $1,062.5$ & 270.529 & 1,250 & 1,118 & 55.94 & 955 \\
\hline 26 & Feb'19 & $1,255.5$ & 275.682 & 1,900 & 551 & 53.53 & 1,125 \\
\hline 27 & Mar'19 & $2,009.0$ & 75.035 & 2,100 & 625 & 82.49 & 1,030 \\
\hline 28 & Apr'19 & $1,789.5$ & 583.495 & 1,700 & 475 & 95.32 & 605 \\
\hline 29 & May'19 & $1,051.0$ & 367.654 & 1,200 & 295 & 51.57 & 381 \\
\hline \multirow[t]{2}{*}{30} & Jun'19 & 247.0 & 215.986 & 500 & 150 & 6.52 & 690 \\
\hline & & $31,579.5$ & $5,984.485$ & 43,470 & 12,750 & $1,700.32$ & 26,776 \\
\hline
\end{tabular}

TABLE II. VALUE OF NORMALITY TEST IN SAPHIRO WILK METHOD

\begin{tabular}{|c|c|c|c|c|}
\hline No. & Model & Statistic & P value & Remark \\
\hline 1 & Ready mixed concrete-concrete steel & 0.974 & 0.641 & normal distribution \\
\hline 2 & Concrete steel-wire & 0.982 & 0.875 & normal distribution \\
\hline 3 & Ready mix concrete-plywood & 0.963 & 0.374 & normal distribution \\
\hline 4 & Plywood-timber & 0.891 & $0.005^{*}$ & non-normal distribution \\
\hline 5 & Timber-nails & 0.874 & $0.002^{*}$ & non-normal distribution \\
\hline
\end{tabular}

- Plywood-timber:

$$
\hat{Y} t=39.29+0.1095 X p
$$

- Timber-nails:

$$
\hat{Y} n=613.76+16.9934 X t
$$

The result of normality retest to the regression of plywood and timber was $\mathrm{P}=0.369$ and the regression of wood and nails was value $\mathrm{P}=0.145$.

\section{2) Heteroscedasticity Test}

The results of heteroscedasticity test with Glejser method are shown in Table III.

3) Modification of the Regression Equations Model with Mathematics Substitution Method Shown (5-10)

- Ready mixed concrete and concrete steel:

$$
\hat{Y} s=-109.92+0.1787 X c
$$

- Ready mixed concrete-wire:

$$
\widehat{Y} w=-1,043.52+1.3684 X c
$$

- Ready mixed concrete-plywood:

$$
\hat{Y} p=-358.95+0.4228 X c
$$

- Ready mixed concrete-timber:

$$
\hat{Y} t=-2.97+0.0463 X c
$$

- Ready mixed concrete-nails:

$$
\widehat{Y} n=563.29+0.7868 X c
$$

TABLE III. HETEROSCEDASTICITY TEST VALUES

\begin{tabular}{|c|c|c|c|c|}
\hline No. & Model & t value & P value & Remark \\
\hline 1 & $\begin{array}{c}\text { Ready mixed concrete - } \\
\text { concrete steel }\end{array}$ & 1.862 & 0.073 & homoscedasticity \\
\hline 2 & Concrete steel -wire & 1.869 & 0.072 & homoscedasticity \\
\hline 3 & $\begin{array}{c}\text { Ready mixed concrete - } \\
\text { plywood }\end{array}$ & 1.715 & 0.097 & homoscedasticity \\
\hline 4 & Plywood-timber & 0.179 & 0.859 & homoscedasticity \\
\hline 5 & Timber-nails & 0.917 & 0.368 & homoscedasticity \\
\hline
\end{tabular}


Note in (1)-(10): $s$ : concrete steel, $w$ : wire, $p$ : plywood, $t$ : timber, $n$ : nails, $c$ : ready mixed concrete

\section{Development of the Material Planning and Controlling Procedure Model}

The obtained regression model of reinforced concrete work materials will be absorbed by the existing procedure. The proposed revision procedure is a corrective plan that adds predictive capabilities based on historically valid information and thus improving the existing procedure. Although there is a volume analysis check, the additional process is necessary in order to minimize the causes of material control difficulties based on research observation results. The model of the procedure of material request submission control can be seen in Figure 1. The additional processes in this revised procedure include:

- A controlling process of the material volume of reinforced concrete works by using the equation reference of regression models. This control uses the regression model of reinforced concrete works as an independent variable by relaying the predictive capability to the needs of various materials of reinforced concrete works.

- An evaluation process of the submission of volume, inventory, and deviation of material waste.

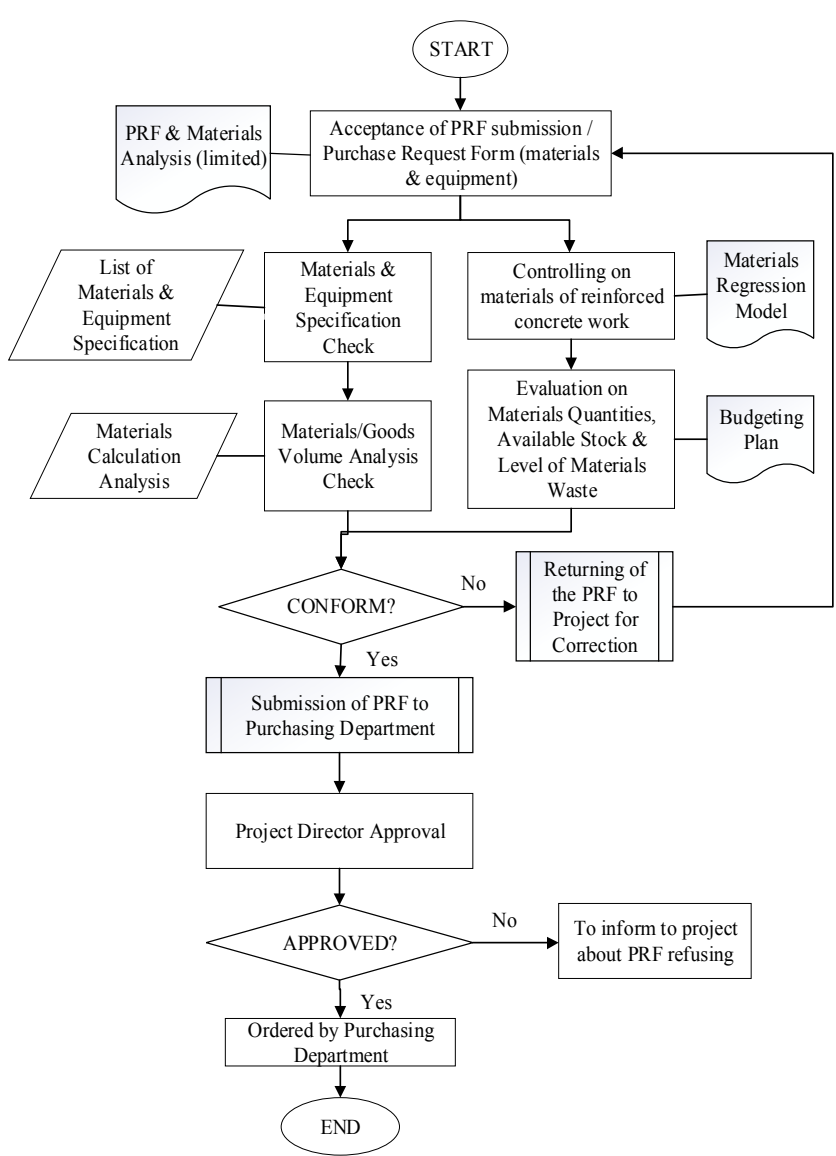

Fig. 1. Flowchart of the revised standard operating procedure

\section{CONCLUSION}

Various project problems that occur in the case of Duta Mall 2 project are caused by material controlling, especially regarding reinforced concrete works. The control of these materials becomes a critical point of the construction process of Duta Mall 2, and aside from its impact to cost it also has impact to the material quality and the schedule of work completion. Effective material control methods are required for complex and dynamic projects such as the construction of Duta Mall 2. The proposed method considers linear regression equation models between various material components of reinforced concrete works based on available historical data. The model equations that are formed can be modified by referring to one independent variable, i.e. the volume of ready mixed concrete. Other material components such as concrete steel, wire, plywood, timber, and nails can be planned more easily and according to its needs. The validated model of the equations can be an analysis tool in the control procedure model for material requests of reinforced concrete works. The evaluation of material waste that occurs can also be done during the works process. Another benefit from the regression model is that it can be a reference of cost budget calculations.

\section{REFERENCES}

[1] M. W. Newell, Preparing for the project management professional, American Management Association, 2002

[2] D. Battini, M. Calzavara, I. Isolan, F. Sgarbossa, F. Zangaro, F. "Sustainability in material purchasing: A multi-objective economic order quantity model under carbon trading", Sustainability, Vol. 2018, No. 10, Article ID 4438, 2018

[3] C. March, Operations management for construction, Taylor and Francis, 2009

[4] I. Suharto, Project management from conceptual to operational, Erlangga, 2017 (in Indonesian)

[5] Project Management Institute, Inc., A guide to the project management body of knowledge, Sixth Edition, Newtown Square, 2017

[6] K. Kupusamy, S. Nagapan, A. H. Abdullah, S. Kaliannan, S. Sohu, S. Subramaniam, H. Maniam, "Construction waste estimation analysis in residential projects of malaysia", Engineering, Technology \& Applied Science Research, Vol. 9, No. 5, pp. 4842-4845, 2019

[7] S. Sohu, A. H. Abdullah, S. Nagapan, T. A. Rind, A. A. Jhatial, "Controlling measures for cost overrun causes in highway projects of Sindh province", Engineering, Technology \& Applied Science Research, Vol. 9, No. 3, pp. 4276-4280, 2019

[8] Q. Yu, K. Li, H. Luo, “A BIM-based dynamic model for site material supply”, Procedia Engineering, Vol. 164, pp. 526-533, 2016

[9] R. E. Walpole, R. H. Myers, Probability \& statistics for engineers \& scientists, 9th edition, Prentice Hall, 2012

[10] M. F. Quadratullah, Applied statistics: Theory, examples of cases and applications with SPSS, Andi Offset, 2014 (in Indonesian)

[11] A. Mursadin, Module of applied statistical Volume 4: Measures of association, University of Lambung Mangkurat, 2019 (in Indonesian) 